\title{
Análise microscópica e ultraestrutural das glândulas salivares mandibulares de Procyon cancrivorus ${ }^{1}$
}

\begin{abstract}
Amilton C. Santos ${ }^{2 *}$, Vanessa C. Oliveira ${ }^{3}$, Diego C. Viana², Luis M. Lobo², Carlos E. Ambrósio ${ }^{3}$, Antônio C. Assis-Neto ${ }^{2}$, Ana F. Carvalho ${ }^{4}$ e Celina A.F. Mançanares ${ }^{3}$

ABSTRACT.- Santos A.C., Oliveira V.C., Viana D.C., Lobo L.M., Ambrósio C.E., Assis-Neto A.C., Carvalho A.F. \& Mançanares C.A.F. 2013. [Microscopy and ultrastructural analysis of mandibular salivary glands of Procyon cancrivorus.] Análise microscópica e ultraestrutural das glândulas salivares mandibulares de Procyon cancrivorus. Pesquisa Veterinária Brasileira 33(Supl.1):39-44. Setor de Anatomia dos Animais Domésticos e Silvestres, Faculdade de Medicina Veterinária e Zootecnia, Universidade de São Paulo, Av. Prof. Dr. Orlando Marques de Paiva 87, São Paulo, SP 05508-030, Brazil. E-mail: amiltonsantoss@usp.br

Due to the ecological importance of Procyon cancrivorus, the aim of this study was to characterize morphologically and ultrastructurally the mandibular salivary gland of this specie. We used 10 pairs (right and left) of mandibular salivary glands from five adult animals. The mandibular salivary glands were dissected and measured by precision calipers and later processed by histological routine technique, stained by HE (hematoxylin and eosin) and Picrossirius. Fragments of the glands were processed for analysis by scanning electron microscopy (SEM). The mandibular salivary gland, right and left from $P$. cancrivorus presents lobulated and oval-shape, and it was positioned between the fossa atlantis and basihyoideum ossis of skull. Microscopically, these glands are lined by a capsule formed by dense irregular connective tissue, which enters into the gland by septa, dividing it into lobules. Into the septa of connective tissue were present blood vessels and nerves, and interlobular excretory ducts. Inside the lobes of the mandibular salivary glands, striatum and intermediate-type ducts are found, and the predominance of mucous acini was observed. The results indicate that the mandibular salivary glands of Procyon cancrivorus, follows the structural pattern described in other mammalian species. However the types of acini may vary among species, and thus further histochemical and cell biology studies are required in order to uncover the significance of this variation for the specie here studied, according with their feeding habit.
\end{abstract}

INDEX TERMS: Procyon cancrivorus, crap-eating-racoon, digestory apparatus, interlobular excretory ducts, mucous acini, Procyonidae.

\footnotetext{
${ }^{1}$ Recebido em 12 de setembro de 2013.

Aceito para publicação em 25 de novembro de 2013.

${ }^{2}$ Faculdade de Medicina Veterinária e Zootecnia (FMVZ), Universidade de São Paulo (USP), Av. Prof. Dr. Orlando Marques de Paiva 87, Cidade Universitária, São Paulo, SP 05508-270SP, Brasil. E-mails: diegoviana@usp. br, miguel_simmons@hotmail.com, antonioassis@usp.br; *Autor para correspondência: amiltonsantoss@usp.br

${ }^{3}$ Faculdade de Zootecnia e Engenharia de Alimentos (FZEA), USP, Avenida Duque de Caxias Norte 225, Pirassununga, SP 13636-900, Brasil. E-mails: van.cristina.oliveira@hotmail.com, celina_furlanetto@hotmail.com, ceambrosio@usp.br

${ }^{4}$ Departamento de Morfologia, Centro Universitário Fundação de Ensino Octávio Bastos (UniFEOB), Avenida Dr. Octávio Bastos, São João da Boa Vista, SP 13870-000, Brasil. E-mail: anaflaviac@uol.com.br
}

RESUMO-- Devido a importância ecológica dos Procyon cancrivorus, o objetivo deste trabalho foi caracterizar morfologicamente e ultra estruturalmente a glândula salivar mandibular desta espécie. Foram utilizadas 10 pares (direita e esquerda) de glândulas salivares mandibulares de cinco animais adultos. As glândulas salivares mandibulares foram dissecadas e mensuradas com paquímetro de precisão e posteriormente processadas por técnica rotineira de histologia e coradas por HE (hematoxilina e eosina) e Picrossírius. Fragmentos das glândulas foram processados para análise em microscopia eletrônica de varredura (MEV). As glândulas salivares mandibulares direitas e esquerdas de $P$. cancrivorus apresentaram-se lobuladas, for- 
mato ovalado, e posicionadas entre a fossa atlantis e o osso basihyoideum do crânio. Microscopicamente, estas glândulas estavam revestidas por uma cápsula de tecido conjuntivo denso não modelado, a qual adentra a glândula através de septos, dividindo-a em lóbulos. Nos septos de tecido conjuntivo estão presentes vasos sanguíneos e nervos, além de ductos interlobulares excretores. Dentro dos lóbulos das glândulas salivares mandibulares, são encontrados ductos do tipo estriado e intercalar, além de predomínio de ácinos do tipo mucoso. Os resultados permitem concluir que as glândulas salivares mandibulares dos Procyon cancrivorus, seguem o padrão estrutural descrito em outras espécies de mamíferos. No entanto os tipos de ácinos podem variar entre as espécies, sendo, portanto, necessários futuros estudos histoquímicos e de biologia celular para desvendar a importância dessa variação para a espécie aqui estudada, comparando com seu hábito alimentar.

TERMOS DE INDEXAÇÃO: Procyon cancrivorus, mão-pelada, ácinos mucosos, aparelho digestório, ductos interlobulares excretores, Procyonidae.

\section{INTRODUÇÃO}

O mão-pelada, Procyon cancrivorus, é um mamífero procionídeo pertencente à ordem Carnivora (Santos et al. 2012, Pereira et al. 2013). As características marcantes dessa espécie são a máscara negra ao redor dos olhos, que se destaca na face esbranquiçada e a região das mãos desprovida de pelos, a qual lhe confere o nome popular de mão-pelada no Brasil (Lima et al. 2010).

Esta espécie possui hábito noturno e crepuscular e sua dieta onívora consiste principalmente de frutas, insetos, anfíbios, peixes, moluscos e caranguejos (Pereira et al. 2013).

Devido ao seu hábito onívoro, Procyon cancrivorus desenvolve importante função de dispersor de sementes dos frutos que fazem parte de sua dieta e são eliminados juntamente com suas fezes (Martinelli \& Volpi 2010), a exemplo de outros animais onívoros como os marsupiais Didelphis albiventris, D. aurita, Metachirus nudicaudatus, Philander frenatus, Lutreolina crassicaudata, Monodelphis sorex e Caluromys lanatus (Cáceres 2005, Cáceres \& Monteiro-Filho 2007) e morcegos (Sato et al. 2008).

Por esta razão as secreções das glândulas salivares, que são órgãos anexos do aparelho digestório, podem desempenhar importante função na digestão de sementes de frutos, através de sua secreção, a saliva. Adicionado a este fato, as glândulas salivares são importantes órgãos para todos os tetrápodes não aquáticos, que precisam das secreções salivares para lubrificar o alimento e auxiliar na mastigação, deglutição e digestão (Orr 1986, Santos et al. 2012). Nestas secreções salivares, estão presentes enzimas como a ptialina que atua na digestão de carboidratos (Dyce et al. 2010), a amilase e a lipase que atuam na digestão de amido e gorduras, além de enzimas antimicrobianas como a imunoglobulina A, a lactoperoxidase, a lisozima e a lactoferrina (Samuelson 2007, Santos et al. 2012).

Devido a importância ecológica e carência de estudos mais detalhados a respeito dos aspectos morfológicos dos órgãos digestórios de Procyon cancrivorus, o objetivo deste trabalho foi caracterizar morfologicamente e ultra estruturalmente pela primeira vez, a glândula salivar mandibular, fornecendo dados para futuras pesquisas relacionadas à morfofisiologia da digestão e os hábitos alimentares desta e de outras espécies.

\section{MATERIAL E MÉTODOS}

Para esta pesquisa foram utilizados cinco pares (esquerdas e direitas) de glândulas salivares mandibulares de cinco mão-peladas, Procyon cancrivorus, sendo três machos e duas fêmeas, adultos, provenientes do CECRIMPAS (IBAMA 02027.002322/98-99), com protocolo de bioética 01.2011 do Centro Universitário Fundação de Ensino Octávio Bastos. Estes animais foram utilizados em pesquisas anteriores a esta, e, portanto, não houve sacrifício de vidas.

As glândulas salivares mandibulares foram dissecadas, identificadas, extraídas e mensuradas com paquímetro de precisão onde foi obtida a média dos resultados. Após a fixação em solução fixadora de formaldeído a $10 \%$, o material foi desidratado em uma série de etanol em concentrações crescentes (de 70 a 100\%), diafanizado em xilol, seguido de inclusão em parafina (Histosec ${ }^{\circledR}$ ) e corado por HE (hematoxilina e eosina) e Picrosírius.

Amostras das glândulas salivares mandibulares também foram fixadas em glutaraldeído a 2,5\% (Propylene oxide EM Grade, Polyciences, Inc., USA), seguido de lavagem em tampão fosfato a 0,1 M pH 7,4 e pós-fixadas em tetróxido de ósmio (Spurr Spurr's kit-Electron Microscopy Sciences, USA) a 1\%, posteriormente imerso em solução de ácido tânico a $2 \%$ e lavado em tampão fosfato e água destilada. As amostras passaram pelo processo de desidratação em álcool etílico em concentrações de 50-100\%. Posteriormente foi feita a secagem em aparelho de ponto crítico Balzers CPD 020, utilizando $\mathrm{CO}_{2}$ líquido. Os fragmentos foram fixados em bases metálicas de alumínio (stubs) com carbono e cobertos com ouro ("sputtering" Emitech K 550) através do aparelho Iom Sputter Balzer - SCD-040, sendo analisado em Microscópio Eletrônico Leo 435 VP.

\section{RESULTADOS}

As glândulas salivares mandibulares direitas e esquerdas de Procyon cancrivorus apresentaram-se lobuladas com formato ovalado, e posicionadas entre a fossa atlantis e o osso basihyoideum. Seu ducto se estendia pela face occiptomandibularis do músculo digástrico e do músculo estiloglosso e se abria próximo ao frênulo da língua. Estava parcialmente coberta pela parte mais ventral da glândula parótida (Fig.1).

Possuem em média 2,93 cm de comprimento, $1,65 \mathrm{~cm}$ de largura e $0,81 \mathrm{~cm}$ de espessura.

Microscopicamente, as glândulas salivares mandibulares de $P$. cancrivorus estavam revestidas por uma cápsula de tecido conjuntivo denso não modelado composto por colágeno do tipo I visualizada pela coloração de Picrossírius. Esta cápsula adentrava a glândula através de septos, dividindo-a em lóbulos. Nos septos de tecido conjuntivo estavam presentes vasos sanguíneos e nervos, além de ductos interlobulares excretores (Fig.2 e 3).

Dentro dos lóbulos das glândulas salivares mandibulares, foram encontrados ductos do tipo estriado e intercalar, além de predomínio de ácinos do tipo mucoso, porém também foram encontrados ácinos do tipo misto (serocomucoso) (Fig.3). 

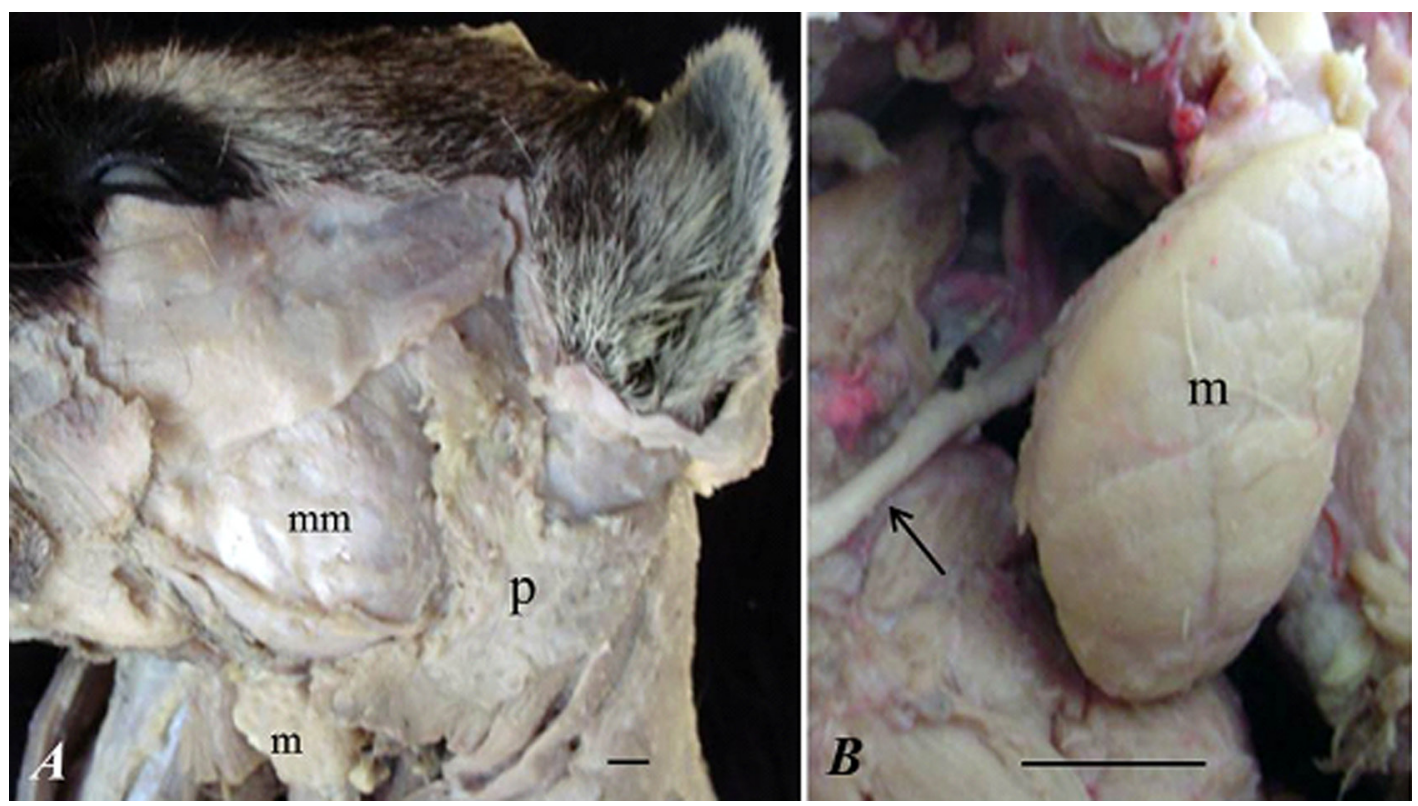

Fig.1. Glândula salivar mandibular esquerda de Procyon cancrivorus. (A) Glândula mandibular (m) posicionada ventralmente a glândula parótida (p) e ao músculo masseter (mm). (B) Formato ovalado da glândula mandibular (m) e seu ducto (seta) seguindo cranialmente em direção ao assoalho da língua. Barra: $1 \mathrm{~cm}$.

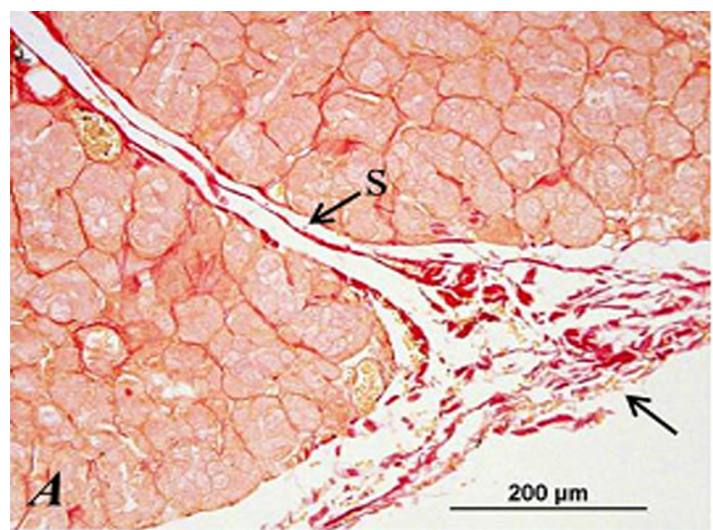

Fig.2. Glândula mandibular de Procyon cancrivorus. (A) Cápsula de tecido conjuntivo (seta) enviando septos (s) para o interior da glândula. Barra $200 \mu \mathrm{m}$. (B) Septos de tecido conjuntivo entre os lóbulos, onde se observam vasos sanguíneos (v) e ductos interlobulares (d). Barra $500 \mu \mathrm{m}$. (C) Ductos interlobulares de diferentes diâmetros (d) e vaso sanguíneo (v). Picrossírius. Barra: $200 \mu \mathrm{m}$.

O epitélio que reveste os ductos intralobulares estriados é do tipo prismático e os ductos intercalares, do tipo cúbico simples. Já na conexão entre os ductos intercalares e os ductos interlobulares foi encontrado epitélio do tipo cúbico com camada dupla (Fig.3).

Através da técnica de microscopia eletrônica de varredura foi possível observar os septos de tecido conjuntivo dividindo a glândula em lóbulos e ductos acinares, ductos intralobulares de menor calibre e ductos interlobulares excretores de maior calibre. Além disso, podem-se observar malhas de fibras colágenas em porções onde esta estava exposta (Fig.4).

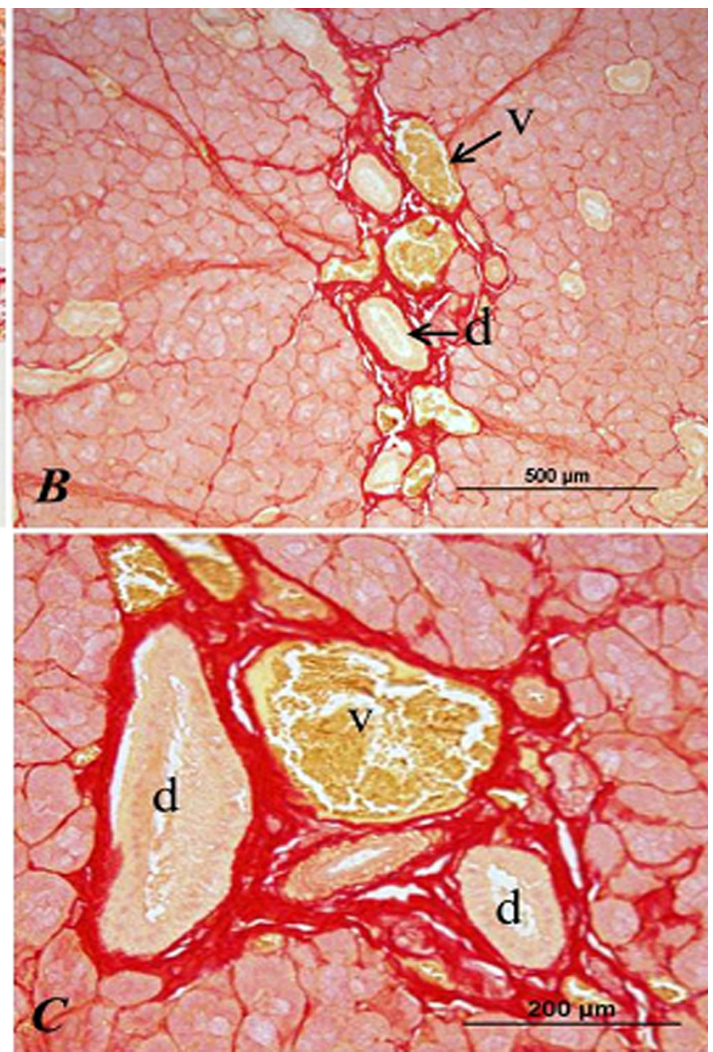

\section{DISCUSSÃO}

Embora os animais Procionídeos onívoros (Santos \& Beisiegel 2006), como Procyon cancrivorus (Martinelli \& Volpi 2010), sejam considerados dispersores efetivos de sementes, e, já sejam criado em cativeiro, buscando sua preservação e desenvolvimento de estudos relacionados a enriquecimento ambiental e hábitos comportamentais e alimentares, poucos estudos relacionados a morfologia e ultraestrutura 


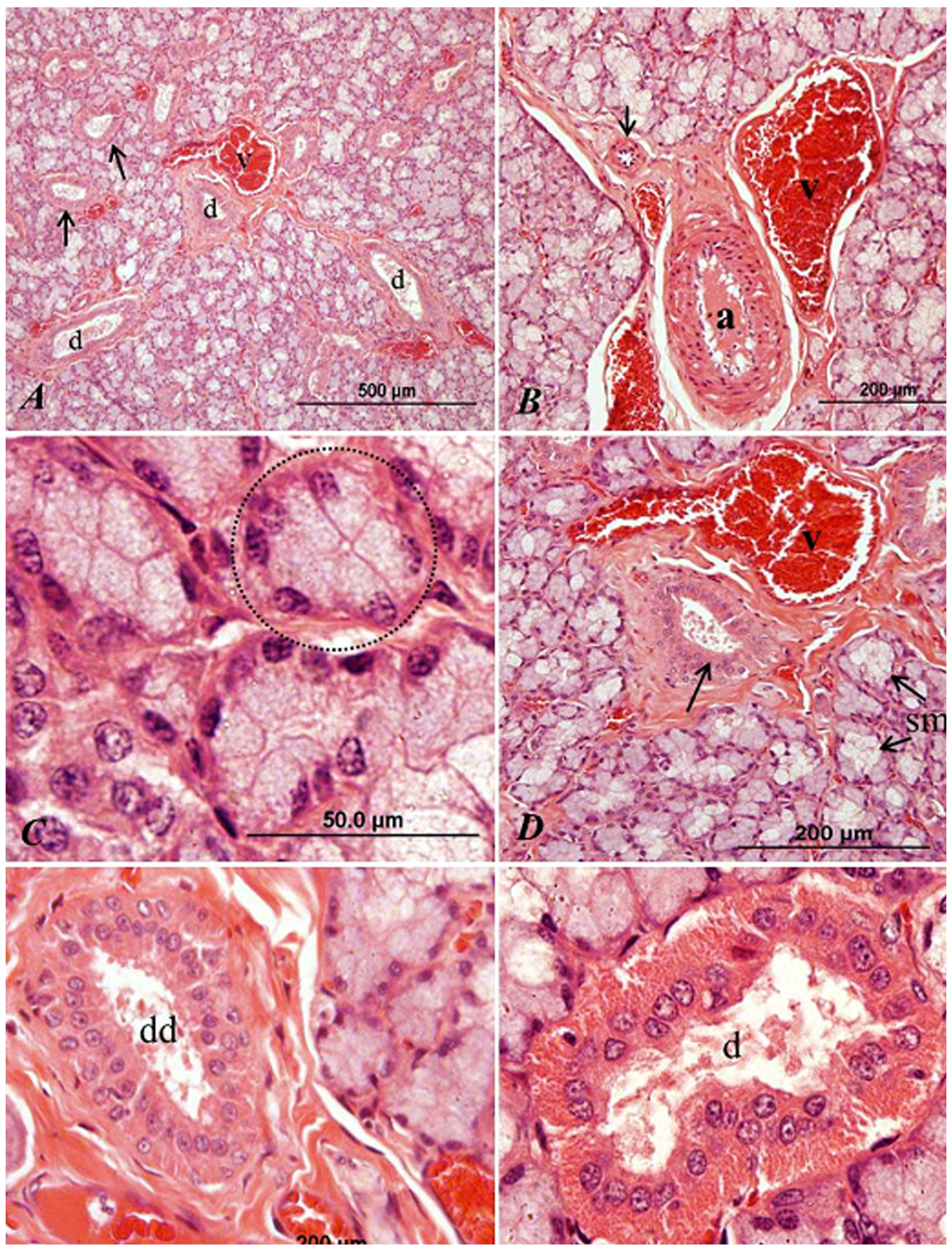

Fig.3. Glândula mandibular de Procyon cancrivorus. (A) Ductos intercalares (d), ductos estriados (setas) e vasos sanguineos (v). Barra:

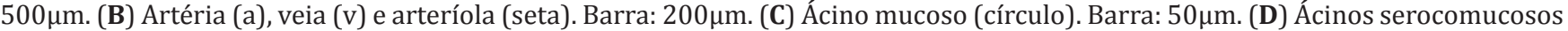

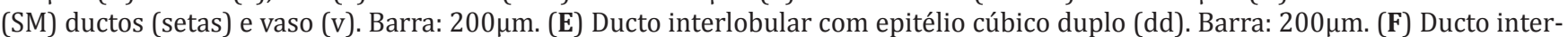
calar com epitélio cúbico simples. HE. Barra: $50 \mu \mathrm{m}$. 

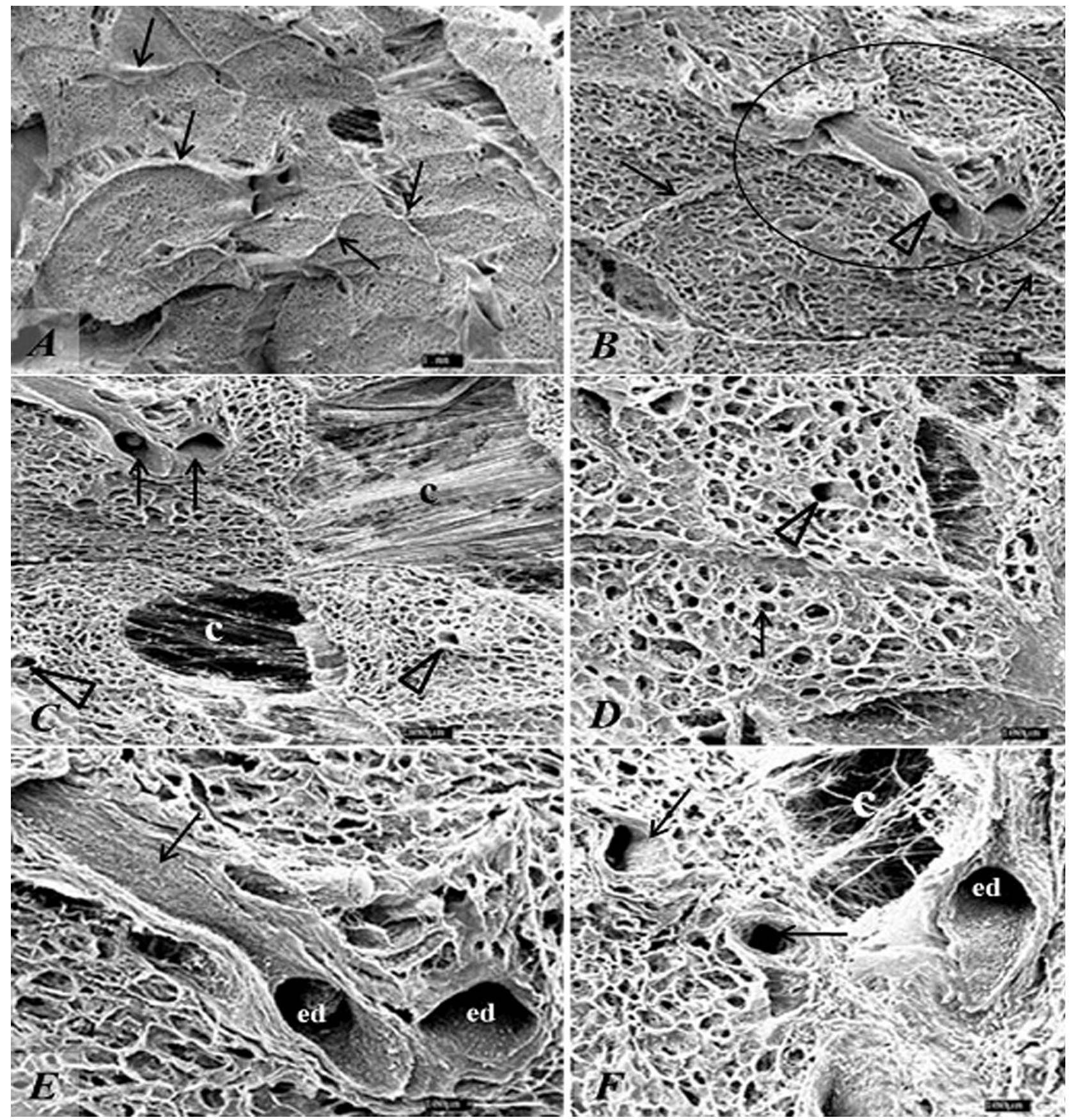

Fig.4. Eletromicrografia da glândula salivar mandibular de Procyon cancrivorus. (A) Septos de tecido conjuntivo (setas). Barra: 1mm. (B) Septo (seta), que se alarga (círculo) na área onde estão posicionados os ductos interlobulares excretores (cabeça de seta). Barra: $300 \mu \mathrm{m}$. (C) Ductos interlobulares excretores (seta), ductos intralobulares (cabeça de seta) e tecido conjuntivo (C). Barra: $300 \mu \mathrm{m}$. (D) Ducto acinar (seta) e ducto intralobular (cabeça de seta). Barra: $100 \mu \mathrm{m}$. (E) Ducto intralobular excretor cortado longitudinalmente (seta) e trans-

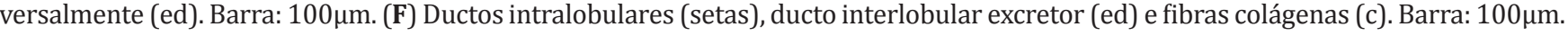

dos órgãos da digestão nesta espécie foram realizados até o momento (Santos et al. 2012, Pereira et al. 2013).

Dessa maneira, este estudo traz a tona detalhados dados microscópicos e ultraestruturais a respeito das glândulas salivares mandibulares em Procyon cancrivorus, relacionando com os hábitos alimentares desta espécie.

No presente estudo, as descrições em relação à posição topográfica da glândula mandibular em Procyon cancrivorus concorda com o detalhado estudo a respeito da anatomia topográfica das glândulas salivares maiores nesta espécie, realizado por Pereira et al. (2013). Além disso, nossos resultados também concordam com os achados em Nasua nasua (Santos et al. 2010), em carnívoros domésticos (cão e gato) (Ellenport 1986) e em Zaedyus pickiy (Estedondo et al. 2005).

Porém, além dos importantes aspectos morfológicos macroscópicos, sabe-se que microscopicamente e ultraestruturalmente, os órgãos podem revelar ainda maiores detalhes, auxiliando na relação forma-função destes.

Por exemplo, as glândulas salivares são formadas por ácinos que podem variar em sua morfologia, a qual está di- 
retamente relacionada com a composição da saliva, que por sua vez, pode variar de acordo com o hábito alimentar da espécie (Banks 1991), sendo que os ácinos mucosos produzem secreção predominantemente glucídica, composta por ácido siálico, mucopolissacarídeos carboxilados e mucopolissacarídeos ácidos sulfatados, enquanto os ácinos serosos produzem secreção proteica (Munhoz 1967).

Na glândula mandibular de P. cancrivorus, a predominância é de ácinos mucosos com alguns poucos ácinos serocomucosos, a exemplo dos artiodátilos Bos taurus e Sus scrofa, dos carnívoros domésticos Canis familiaris e Felis catus e dos roedores Rattus novergicus e Cricetus auratus, descritos por Munhoz (1967). Resultado diferente de P. cancrivorus, é encontrado em camundongos, que apresentam ácinos mucosos e serosos (Pícoli et al. 2011) e nos procionídeos Nasua nasua, que possuem glândulas mandibulares com predominância de ácinos serocomucosos, com presença de alguns poucos ácinos puramente serosos (Santos et al. 2010).

Esta diferença nos ácinos da glândula mandibular entre Procyon cancrivorus e Nasua nasua, é um achado intrigante, devido às duas espécies serem da mesma família e possuírem hábito alimentar onívoro, sendo que as glândulas parótidas nestas espécies possuem o mesmo tipo de ácinos serosos (Santos et al. 2012).

Esta variação na glândula mandibular, mas não na glândula parótida, pode estar relacionada a pequenas modificações alimentares, decorrentes dos alimentos encontrados em diferentes habitats onde estas espécies são encontradas (Santos \& Beisiegel 2006, Martinelli \& Volpi 2010).

Além dos ácinos, o interior da glândula mandibular de Procyon cancrivorus, apresentam também revestimento e estruturas internas como ductos, vasos e nervos, descrito também em camundongos (Pícoli et al. 2011), carnívoros domésticos (Dyce et al. 2010) e nos procionídeos Nasua nasua (Santos et al. 2010).

Ultraestruturalmente, os ductos intralobulares estriados possuem células epiteliais que influenciam no conteúdo iônico e de água da secreção. Já a superfície basal possui invaginações e interdigitações na membrana plasmática, que associadas a grande quantidade de mitocôndrias (Pícoli et al. 2011), servem para o movimento rápido de fluídos e íons que dão a característica estriada ao ducto (Banks 1991).

Nesta pesquisa, consideramos que as glândulas salivares mandibulares de P. cancrivorus, em relação à estrutura dos ductos e lobulação promovida por septos de tecido conjuntivo com fibras colágenas, que se originam na cápsula e adentram o órgão, seguem o padrão estrutural descrito em outras espécies de mamíferos. No entanto os tipos de ácinos variam entre as espécies.

Portanto, sugere-se que animais com hábitos alimentares diferentes podem apresentar diferentes constituições acinares nas glândulas salivares mandibulares, mesmo em espécies de animais da mesma família, sendo que futuros estudos histoquímicos e de biologia celular poderão desvendar a importância dessa variação na espécie aqui estudada.

\section{CONCLUSÕES}

Os resultados permitem concluir que as glândulas salivares mandibulares de Procyon cancrivorus seguem o padrão estrutural descrito em outras espécies de mamíferos.

No entanto os tipos de ácinos podem variar entre as espécies, sendo, portanto, necessários futuros estudos histoquímicos e de biologia celular para desvendar a importância dessa variação para a espécie aqui estudada, de acordo com seu hábito alimentar.

Agradecimentos.- À Fundação de Amparo a Pesquisa do Estado de São Paulo (FAPESP) pelo suporte financeiro (13/02535-9) da pesquisa, ao Instituto Brasileiro do Meio Ambiente e dos Recursos Renováveis (IBAMA) pelo licenciamento da pesquisa, e à Professora Doutora Rose Eli Grassi Rici pelo suporte técnico.

\section{REFERÊNCIAS}

Banks W.J. 1991. Histologia Veterinária Aplicada. 2ª ed. Manole, São Paulo. 629 p.

Cáceres N.C. 2005. Comparative lengths of digestive tracts of seven didelphid marsupials (Mammalia) in relation to diet. Revta Bras. Zool. 22(1):181-185.

Cáceres N.C. \& Monteiro-Filho E.L.A. 2007. Germination in seed species ingested by opossums: implications for seed dispersal and forest conservation. Braz. Arch. Biol. Technol. 50(6):921-928.

Dyce K.M., Sack W.O. \& Wensing C.J.G. 2010. Tratado de Anatomia Veterinária. 4aㅡ ed. Guanabara Koogan, Rio de Janeiro. 834p.

Ellenport C.R. 1986. Sistema digestivo, p.1445-1464. In: Getty R. (Ed.), Anatomia dos Animais Domésticos. Vol.2. 5a ed. Interamericana, Rio de Janeiro. 2000p.

Estecondo S., Codón S.M. \& Casanave E.B. 2005. Histological study of the salivary glands in Zaedyus pichiy (Mammalia, Xenarthra, Dasypodidae). Int. J. Morphol. 23(1):19-24.

Lima V.M., Pereira F.C. \& Pereira K.F. 2010. Estudo morfológico dos músculos do antebraço do mão-pelada, Procyon cancrivorus (Cuvier, 1798). Biosc. J. 26(1):109-114.

Martinelli M.M. \& Volpi T.A. 2010. Diet of racoon Procyon cancrivorus (Carnivora, Procyonidae) in a mangrove and restinga area in Espirito Santo state, Brazil. Nat. online 8(3):150-158.

Munhoz C.O.G. 1967. Estudo histoquímico comparativo (proteínas e carboidratos) das glândulas salivares maiores de três ordens de mamíferos (artiodáctilos, carnívoros e roedores). Tese de Doutorado, Faculdade de Odontologia de Piracicaba, Universidade de Campinas, Piracicaba. 118p.

Orr R.T. 1986. Biologia dos Vertebrados. 5a ed. Roca, São Paulo. 508p.

Pereira K.F., Souza D.R., Ferreira L.S., Chela P.R., Helrigle C. \& Araújo E.G. 2013. Morphological aspects of the salivary glands of Crab-eating raccoon (Procyon cancrivorus). Acta Scient. Biol. Sci. 35(1):99-103.

Pícoli L.C., Dias F.J., Issa J.P., Ogawa K., Ciena A., Iyomasa M.M., Lopes R.A. \& Watanabe I.S. 2011. Ultrastructure of submandibular salivary glands of mouse: TEM and HRSEM observations. Microsc. Res. Tech. 74(6):11541160.

Santos A.C., Bertassoli B.M., Oliveira V.C., Rosa R.A., Carvalho A.F. \& Mançanares C.A.F. 2010. Caracterização morfológica das glândulas salivares mandibulares dos quatis (Nasua nasua Linnaeus, 1758). Revta Fac. Zootec. Vet. Agron., Uruguaiana, 17(2):276-286.

Santos A.C., Bertassoli B.M., Oliveira F.D., Oliveira D.M., Oliveira V.C., Vasconcelos B.G., Carvalho A.F., Mançanares C.A.F. \& Assis-Neto A.C. 2012. Estrutura macro e microscópica das glândulas salivares parótidas em duas espécies de procionídeos: mão-pelada (Procyon cancrivorus G. Cuvier, 1798) e quati (Nasua nasua Linnaeus, 1766). Revta Biotemas 25(1):93-101.

Santos V.A. \& Beisiegel B.M. 2006. A dieta de Nasua nasua (Linnaeus, 1766) no Parque Ecológico do Tietê, SP. Revta Bras. Zoociênc. 8(2):199-203.

Sato T.M., Passos F.C. \& Nogueira A.C. 2008. Frugivoria de morcegos (Mammalia, Chiroptera) em Cecropia pachystachya (Urticaceae) e seus efeitos na germinação das sementes. Papéis Avulsos Zool. 48(3):19-26. 